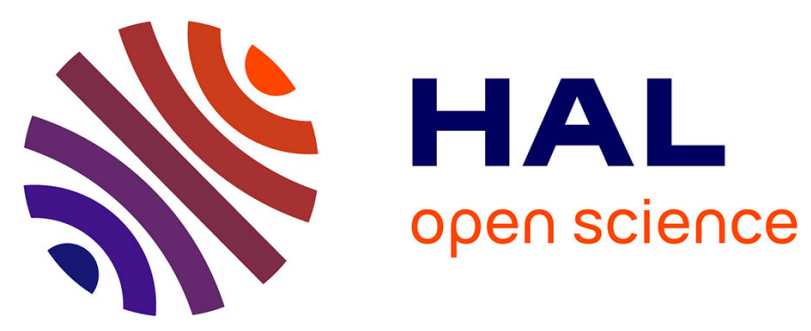

\title{
Self-reference effect on memory in healthy aging, mild cognitive impairment and Alzheimer's disease: Influence of identity valence
}

Mona Leblond, Mickaël Laisney, Virginie Lamidey, Stéphanie Egret, de La Sayette, Gaël Chételat, Pascale Piolino, Géraldine Rauchs, Béatrice

Desgranges, Francis Eustache

\section{To cite this version:}

Mona Leblond, Mickaël Laisney, Virginie Lamidey, Stéphanie Egret, de La Sayette, et al.. Selfreference effect on memory in healthy aging, mild cognitive impairment and Alzheimer's disease: Influence of identity valence. Cortex, 2015, 74, pp.177-190. 10.1016/j.cortex.2015.10.017 . inserm01226394

\section{HAL Id: inserm-01226394 https://www.hal.inserm.fr/inserm-01226394}

Submitted on 9 Nov 2015

HAL is a multi-disciplinary open access archive for the deposit and dissemination of scientific research documents, whether they are published or not. The documents may come from teaching and research institutions in France or abroad, or from public or private research centers.
L'archive ouverte pluridisciplinaire HAL, est destinée au dépôt et à la diffusion de documents scientifiques de niveau recherche, publiés ou non, émanant des établissements d'enseignement et de recherche français ou étrangers, des laboratoires publics ou privés. 


\section{Research report}

\section{Self-reference effect on memory inhealthyaging,mild cognitive}

impairment and Alzheimer's disease:Influence of identity valence

Mona Leblond ${ }^{\mathrm{a}, \mathrm{b}, \mathrm{c}, \mathrm{d}}$, MickaëlLaisney ${ }^{\mathrm{a}, \mathrm{b}, \mathrm{c}, \mathrm{d}}$, VirginieLamidey ${ }^{\mathrm{f}}$, StéphanieEgret $^{\mathrm{a}, \mathrm{b}, \mathrm{c}, \mathrm{d}}$, Vincent de La Sayette $^{\mathrm{a}, \mathrm{b}, \mathrm{c}, \mathrm{e}}$, GaëlChételat ${ }^{\mathrm{a}, \mathrm{b}, \mathrm{c}, \mathrm{d}}$, Pascale Piolino ${ }^{\mathrm{g}, \mathrm{h}}$, GéraldineRauchs ${ }^{\mathrm{a}, \mathrm{b}, \mathrm{c}, \mathrm{d}}$, BéatriceDesgranges $^{\mathrm{a}, \mathrm{b}, \mathrm{c}, \mathrm{d}}$, Francis Eustache $\mathrm{F}^{\mathrm{a}, \mathrm{b}, \mathrm{c}, \mathrm{d}^{*}}$

${ }^{\mathrm{a}}$ INSERM U1077, 14000 Caen, France

${ }^{\mathrm{b}}$ Université de Caen Basse-Normandie, UMR-S1077, 14000 Caen, France

${ }^{c}$ Ecole Pratique des Hautes Etudes, UMR-S1077, 14000 Caen, France

${ }^{\mathrm{d}} \mathrm{CHU}$ de Caen, U1077, 14000 Caen, France

${ }^{\mathrm{e}} \mathrm{CHU}$ de Caen, Service de Neurologie, 14000 Caen, France

${ }^{\mathrm{f}}$ Centre Hospitalier de Lisieux, 14100 Lisieux, France

${ }^{\mathrm{g}}$ INSERM U894, 75006 Paris, France

${ }^{\mathrm{h}}$ Université Paris Descartes, UMR-S894, 75006 Paris, France

* Correspondence to: Francis Eustache; Laboratoire de Neuropsychologie et de Neuroanatomie de la Mémoire Humaine, Unité de Recherche U1077 Inserm - EPHE Université de CaenNormandie, Pôle des Formations et de Recherche en Santé, 2 Rue des Rochambelles, CS 14032, 14032 CAEN cedex 5,Tel.: +33 2315683 90, E-mail: francis.eustache@inserm.fr 


\begin{abstract}
The self-reference effect (SRE) has been shown to benefit episodic memory in healthy individuals. In healthy aging, its preservation is acknowledged, but in Alzheimer's disease (AD), the jury is still out. Furthermore, there has yet to be a study of the SRE in amnesticmild cognitive impairment (aMCI). As self-reference implies subjective self-representations, and positive information enhance memory performance, weset out to examine the effects of 1) material and 2) identity valence on the SRE across the early stages of AD. Twenty healthy older individuals and 40 patients (20 diagnosed withaMCI and 20 diagnosedwith mild AD) performed a memory task. Participants had to judge positive and negative personality trait adjectiveswith reference to themselvesor to anotherperson, or elseprocess these adjectives semantically. We then administered a recognition task. Participants also completed a questionnaire on identity valence. Among healthy older individuals, the SRE benefited episodic memory independentlyof materialand identity valence. By contrast, among aMCI patients,we only observed the SRE when the material was positive. When self-referential material was negative, patients'performancedepended on the valence of their selfrepresentations: negative self-representations correlated with poor recognition of negative self-referentialadjectives. Finally, performance of patients with mild AD by condition and material valence were too low and inappropriate to be subjected to relevant analyses. The persistence of anSRE for positive adjectivesin aMCI suggests theexistence of a positivity effect for self-related information, which contributes to wellbeing. The absence of an SRE for negative adjectives, which led aMCI patients to dismiss negative self-related information, could be due to low self-esteem. These results corroborate the mnenic neglect model andpoint outthe importance of the psychoaffective dimension in patients with aMCI, which couldconstitute a major factor for the preservation of their self-esteem and selfrelatedmemory.
\end{abstract}


Keywords: self-reference effect; positivity effect;episodic memory; amnesticmild cognitive impairment; Alzheimer's disease 


\section{Introduction}

The memory advantage conferred by self-referentialinformation has been of considerableinterest to psychologists for more than 40 years. In 1977, Rogers, Kuiper, and Kirkerreported that self-reference constitutes arich and powerful encoding process. In their groundbreakingself-reference effect (SRE) paradigm, young participants had to rate trait adjectives that ranged in depth of encoding from structural and phonemic tosemantic, and finally self-referential. This paradigm relied on the levels-of-processing framework for human memory devised by Craik and Lockhart (1972) and Craik and Tulving (1975). Briefly, experiments showed that the persistence of the episodic memory trace depended on the depth of analysis, with greater depth corresponding to a greater degree of semantic involvement from the participants. Deep encoding (semantic)would lead to betterepisodic memory performance than shallow encoding (structural or phonemic). Rogers et al. (1977) then demonstrated that a self-referential conditionwas leadingto deeper encoding than a semantic condition, as the subsequent memory task yielded better performance when individuals had referred the trait adjectives to themselves.

Numerous studies conducted in healthy individualshave confirmed the considerablepotential effect of the SRE on recognition performance (seeSymons \& Johnson, 1997, for a review) and its robustness across the adult lifespan (Morel et al., 2014; Glisky \& Marquine, 2009; Gutchess, Kensinger, Yoon, \& Schacter, 2007;Mueller, Wonderlich, \& Dugan, 1986). Furthermore, although healthyolderindividuals have difficulty retrieving specific details from the encoding context (see Johnson, Hashtroudi, \& Lindsay, 1993, for a review),there is evidence that this episodic memory deficit in aging can be counteracted by self-reference during encoding (Dulas, Newsome, \& Duarte, 2011; Hamami, Serbun, \& Gutchess, 2011), which is thought to promote recollection-based processes. This process has 
been named the self-reference recollection effect(SRRE;Conway, Dewhurst, Pearson, \& Sapute, 2001).

The self may not be a unitary entity, but rather a multiplicity of interrelated processes and contents. According to Klein and Gangi (2010), episodic and semantic memory both contribute to the sense of self. One specific type of self-knowledge is semantic summary representations of one's personality traits, which necessarily depend on how one perceives oneself (positively or negatively). Sense of identity through personality trait-knowledge hasinterestingly been shown to be peculiarly resilient in patients with Alzheimer's disease (AD). Most of the time, these patients exhibit a preserved sense of identity (Eustache et al., 2013; Klein, Cosmides, \& Costabile, 2003; Rankin, Baldwin, Pace-Savitsky, Kramer, \& Miller, 2005), along with a general positive view of themselves when compared with healthy older individuals (Eustache et al., 2013; Kalenzaga \& Clarys, 2013; Lalanne, Rozenberg, Grolleau, \& Piolino, 2013). It has been suggested that their inability to learn new information and update knowledge about their current self could explain why they continue to maintain a positive view of themselves, despite the disease (Lalanne et al., 2013; Naylor \& Clare, 2008). To ourknowledge, no study hasyetinvestigated the sense of self in aMCI. Given that aMCI and $\mathrm{AD}$ could be seen as a continuum, we can speculate that the sense of identity in aMCI patients is relatively preserved as well. In particular, aMCI patients should display a relatively positive sense of identity when compared with healthy older individuals.

Very few studies have investigated theadvantage ofself-referentialpersonality traits on episodic memoryperformance in AD.The literature is young, scarce, and thus divided. Some studies have compared recognition performance for self-referential adjectives (i.e., "Does the adjective describe you?") and semantically processed adjectives (i.e, "Is the adjective positive?"), while others have compared recognition performance for self-referred and otherreferred (i.e., judgments of celebrities) adjectives. Usually, the SRE was evaluatedwitha 
simple yes/no recognition task yielding a recognition rate, while the SRRE was evaluated by means of the Remember/Know $(\mathrm{R} / \mathrm{K})$ paradigm, yielding a recollection rate. The $\mathrm{R} / \mathrm{K}$ paradigmallows episodic memory to be assessed through autonoetic consciousness (Gardiner, 1988; Tulving, 1985,2002). Remember (R) responses involve episodic memory: they reflect the recollection of contextual details that give onethe impression of traveling back in time and reliving past experiences. By contrast, know $(\mathrm{K})$ responses are assumed to reflect a feeling of familiarity without recollection, via semantic memory processes. In Genon et al. study (2014), two encoding conditions were used (self-referential vs. other-referential). Their results revealed neither SRE, nor SRRE in AD patients. The absence of an SRE in patients with $A D$ has also been observed with a memory task including a self-referential condition and a semantic condition (i.e., "does the adjective represent a socially desirable trait?";Lalanne et al., 2013). By contrast, an SRE was found when patients with AD performed a memory task featuring a self-referential condition and an other-referential condition (Kalenzaga \& Clarys, 2013). The SRRE has also been found in patients with AD in studies focusing on the valence of the personality traits used for self-reference. In Lalanne et al. (2013), an SRRE was observed exclusively for positive words in a memory task that also featured a semantic encoding condition for the sake of comparison. By contrast, in Kalenzaga and Clarys (2013) and Kalenzaga, Bugaïska, and Clarys (2013), the SRRE was observed exclusively for negative words, regardless of the nature of the comparison condition (other-referential or semantic).

These conflicting results maystem fromdifferences in methodology, such as the use of intentional (Genon et al., 2014; Kalenzaga\&Clarys, 2013, Kalenzaga et al., 2013) versus incidental encoding conditions (Lalanne et al., 2013),or the length of the retention interval between the encoding and recognition/retrieval conditions, which can range from ten seconds (Genon et al., 2014) to one minute (Kalenzaga\&Clarys, 2013, Kalenzaga et al., 2013) or even 
20 minutes (Lalanne et al., 2013). Anothermethodological difference that could have led to these contradictory results isthe setting of the memory task: either inside (Genon et al., 2014) or outside an MRI scanner (Kalenzaga\&Clarys, 2013, Kalenzaga et al., 2013; Lalanne et al., 2013). However, one result yielded by some of these studies is the poor overall memory performance displayed by patients with AD. For this reason, a study of the SRE among patients with less impaired cognitive functioning, but who are at risk for developing $\mathrm{AD}$, would be particularly useful. In this respect, patients with amnestic mild cognitive impairment (aMCI) constitute appropriate candidates.

Episodic memory impairment constitutes the inaugural and most long-lasting prevailing symptom in AD (see Salmon \& Bondi, 2009, for review). However, cognitive impairments in AD start insidiously and evolve progressively. Patients therefore experience a transient phase during which cognitive deficits are detectable, but are not of sufficient severity to meet the criteria for dementia. This transient phasegave rise to the concept of MCI, first proposed by Flicker, Ferris, and Reisberg (1991) and then refined byPetersen et al. (1999). In front of the apparent heterogeneity among these patients, the definition has nowadays been refined to provide crucial diagnosis tools for clinical and research ends (Petersen et al., 2001; Petersen, 2003; Winblad et al., 2004; Gauthier et al., 2006). Two subtypes of MCI patients are now distinguished: amnestic and non-amnestic. The amnesic subtype of MCI is considered as a syndrome in which episodic memory decline is greater than expected for an individual's age and education level but that does not impact on activities of daily living. Memory impairments are usually associated with a memory complaint expressed by the patient.It is one of the most potential prodromal, symptomatic but pre-dementia stages of AD (Petersen \& Morris, 2005).Besides, the decline of episodic memory in aMCI patients has been observed with both verbal and visual tasks (Crowell, Luis, Vanderploeg, Schinka, \& Mullan, 2002; Petersen et al., 1999). Some studies suggest that episodic memory troubles in aMCI 
would be associated to a deficit in the consolidation of information that is similar to the one observed in AD (Crowell et al., 2002; Chételat et al., 2005; Perri, Carlesimo, Serra, \& Caltagirone, 2005). aMCI patients alsoexperiencedifficulties to use strategies at the time of encoding and show impairmentduringretrieval. As such, patients with aMCI do less semantic clustering during learning (Ribeiro, Guerreiro, \& De Mendonça, 2007) and show elevated intrusion errors during recall, as well as poor recognition performance with increased false positive (Greenaway et al., 2006). Finally, aMCI patients present reduced autonoetic consciousness, as measured using the R/K paradigm (Irish, Lawlor, O’Mara, \& Coen, 2010; Rauchs et al., 2007). Altogether, these results suggest that aMCI patients show memory patterns very close to what can be observed in AD.

With regard to the literature on emotion and valence, in healthy individuals, emotionally-laden materialhave been shown to enhance memory (seeNeisser \& Libby, 2000 andKensinger, 2004, for a review). Furthermore, healthy older adultshave a tendency to focus their attention on positive information (Mather \& Carstensen, 2003; and seeMather \& Carstensen, 2005, for a review). This attention bias for positive information is believed to improve memory (the so-called positivity effect), as the more information is attended, the more likely it is to be remembered later on(Carstensen, 2006). Regarding aMCI and $\mathrm{AD}$,research on the impact of emotion and/or valence on memoryhas provided mixed results, reporting either an effect of emotion (Giffard, Laisney, Desgranges, \& Eustache, 2015; ), no effect of emotion(Abrisqueta-Gomez, Bueno, Oliveira, \& Bertolucci, 2002; Kensinger, Brierley, Medford, Growdon, \& Corkin, 2002), an effect of positive valence(Kalenzaga, Piolino, \& Clarys, 2014; Maki, Yoshida, Yamaguchi, \& Yamaguchi, 2013; Werheid, McDonald, Simmons-Stern, Ally, \& Budson, 2011; Werheid et al., 2010) or an effect of negative valence(Kalenzaga \& Clarys, 2013; Kalenzaga et al., 2013; Döhnel et al., 2008;Boller et al., 2002). The question of whether the effect of emotionally-laden material on 
memory is maintained through self-reference across the spectrum of ADpathology still requires much more investigation.

In the present study, we first aimed to investigate the effect of material valence (personality trait adjectives) on changes in the SRE in patients with aMCI. Episodic memory is less impaired in patients with aMCI thanin patients with $\mathrm{AD}$. We therefore reasoned that studyingthis prodromal stage might avoid poor episodic memory performance, whichcouldsometimes lead to conflicting resultsreported in the literature on the SRE in AD. The overall memory performance of patients with mild AD would be poorer than those of patients with aMCI and in a similar vein, the overall memory performance of patients with aMCI would be poorer than thoseof healthy older individuals. We predictedthat the SRE would be maintained in patients with aMCI and mild AD whencompared with healthy older individuals, but wouldvary in amplitude as a function of material valence. In the second part of our study, we examined whether the valence of identity influenced changes in self-related memory performance within each group, as the SRE necessarily relies on subjective selfrepresentations. We therefore studied the SRE in healthy older individualsand patients with aMCI and mild AD, by administering a memory task that featuredone self-referential encoding condition and two control encoding conditions (other-referential and semantic) andaccounting for the valence of the material used and the valence of identity.

\section{Material and Methods}

\subsection{Participants}

A total of 60 right-handed native French-speaking participants were included in the study: 20 healthy controls (HC; 11 men; 9 women; mean age $\pm S D: 71.60 \pm 5.25$ years), 20 patients with aMCI (9 men; 11 women; mean age $\pm S D: 74.15 \pm 6.30$ years) and 20 patients with mild $\mathrm{AD}$ (15 men; 5 women; mean age $\pm S D: 69.10 \pm 9.27$ years). Ten of the 20 
patientswith mild AD had to be excluded from the analyses because their cognitive deficits were too severe (they did not understand the instructions for the memory task). We nonetheless reported a description of the neuropsychological screening obtained from the patients with mild AD that were excluded. Someof the participants included in the present study were previously involved in other publications (Perrotin et al., 2015; La Joie et al., 2012; 2013; 2014).HC were recruited from the community on a voluntary basis and enrolled in the study after clinical and neuropsychological examinations. They were screened for abnormalities according to stringent inclusion/exclusion criteria, including (1) normal somatic examination; (2) no known vascular risk factor and smoking less than 10 cigarettes per day; (3) no alcohol or drug abuse; (4) normal standard T1- and T2-weighted magnetic resonance imaging (MRI) scans, as assessed by aphysician; (5) no clinical evidence of chronic neurological, psychiatric, hepatic, infectious or endocrine diseases (except for hypothyroid or stable diabetes); (6) no past history of severe disease; and (7) no current use of medication (except for estrogen replacement therapy and antihypertensive drugs). All HC had performanceswithin the normal range (i.e., within 1.65 SD of the normal mean for age) in all neuropsychological screening tests, which included cognitive tasks assessing verbal and visual episodic memory (RL/RI-16,Van der Linden \& Juillerat, 2004; ESR, Eustache, Desgranges, \& Lalevée, 1998; and BEM-144 figure recall, Signoret, 1991), and scales assessing overall cognitive functioning (Mini Mental State Examination, MMSE;Folstein, Folstein, \& McHugh, 1975; Mattis Dementia Rating scale, MDRS;Mattis, 1976) and depressivesymptoms (Montgomery and Åsberg Depression Rating Scale, MADRS;Montgomery \&Åsberg, 1979). Finally, none expressed any complaints about their memory.

The patients with aMCI and AD were recruited from local memory centers, and were enrolled in the study according to the same stringent inclusion/exclusion criteria as $\mathrm{HC}$ 
(excepting criteria 4) and 5)), plus an eighth criterion: no current anticholinesterase and/or memantinetreatment. The patients with AD were diagnosed using NINCDS-ADRDA criteria for probable AD (McKhann et al., 1984), and were at the mild stage of the disease (MMSE between 19 and 24, Feldman \& Woodward, 2005). They underwent the same neuropsychological tests as HC. Overall cognitive functioning was assessedwith the MMSE and MDRS, and depressivesymptoms were investigated with the MADRS. Data from other neuropsychological screening tests (RL-RI 16, ESR,BEM-144 figure recall) were sometimes missing.Patients withaMCI were diagnosed according to the criteria defined byPetersen and Morris (2005). These included the presence of a memory complaint, objective episodic memory deficits but preservation of other cognitive functions, autonomy in daily life, and absence of dementia.

The study was approved by the regional ethics committee (CPP Nord-Ouest III), carried out in line with the Declaration of Helsinki, and registered at ClinicalTrials.gov (no. NCT01638949). All participants (and a close relative for the patients with AD) gave their written informed consent to the study prior to the investigation.

\subsection{Memory task}

The memory task,anadaptation of ones used in previous studies (Johnson et al., 2007; Kelley et al., 2002; Moran, Heatherton, \& Kelley, 2009),hadpreviouslybeen validated in ourlaboratory in healthyyoungparticipants(Morel et al., 2014). It included a self-referential condition administered in an MRI scanner.The neuroimaging data are not reported in this publication.

The memory task consisted ofan incidental encoding session immediately followed by a yes/no recognition session. The encoding and recognition sessions were each divided in two parts, of similar design. The sessions were block-designed to allow for a break and reduce participantfatigue. 
In each session (encoding/recognition), adjectives weredisplayed on a screen for 3500 $\mathrm{ms}$, along with brief instructions as to the nature of the task to be performed, followed by a fixation cross for 1000-3000 ms (mean: 2000 ms) (see Fig. 1). Items were displayed using EPrime software (Psychology Software Tools, Pittsburgh, PA, USA) implemented within IFIS System Manager (Invivo, Orlando, FL, USA).

The encoding session was divided into three nested conditions, each corresponding to a specific type of judgment. For each personality trait adjective, participants were asked to perform one of three types of judgment: 1) self-related ("Does this adjective describe you?"), 2) distant other-related ("Does this adjective describe Jacques Chirac?" - French president from 1995 to 2007 or "Does this adjective describe Johnny Hallyday?" - French singer), or 3) semantic (“Is this a positive adjective?"). Each part lasted about 7 minutes and contained 72 adjectives, with the same proportions of positive and negative ones (12 positive self, 12 negative self, 12 positive other, 12 negative other, 12 positive semantic, 12 negative semantic).

In the recognition task, participants had to determine whether or not they had encountered theadjective displayed on the screen during the previous encoding session (“Old?”). Each retrieval session lasted around 8 minutes and included 84 adjectives (30 new distractoradjectives, 18 old self, 18 old other, and 18 old semantic, with the same number of positive and negative items in each category).

The SRE was estimated on accuracy scores (proportion of hits minus proportion of false alarms),comparing memory performances for 1) self- versusdistant other-referred adjectives and 2) self-referred versus semantically processed adjectives. As such, the distantother and semantic conditions served ascontrolconditions. 
A pre-experimental training session was performed 15 minutes before the encoding session, to familiarize the participants with the task. The adjectives presented during this training session were different from those presented during the encoding session.

The material consisted of 204 personality trait adjectives selected from 463 adjectives drawn from a French language dictionary (http://atilf.atilf.fr/). Their selection was based on familiarity and valence ratings provided in a pre-experiment by young and older individuals with low and high levels of education. The 204 selected adjectives were divided into sixlists of 24 adjectives(one list for each condition), and two lists of 30 adjectives to serve as distractors in the retrieval session. The adjectives in these eight lists were counterbalanced for familiarity, valence, and number of letters, so that these parameters did not differ between conditions. The lists were also counterbalanced across participants.

\section{Encoding phase}
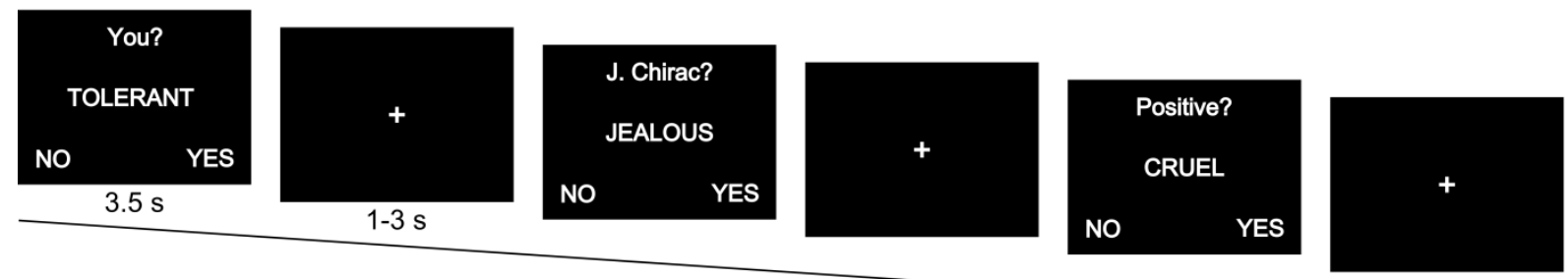

Recognition phase

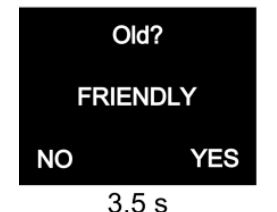

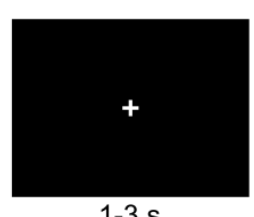

$1-3 \mathrm{~s}$
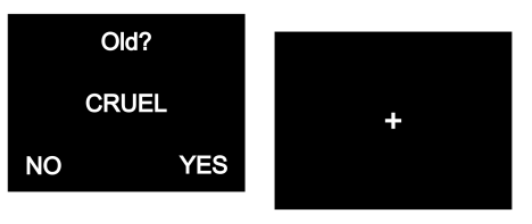
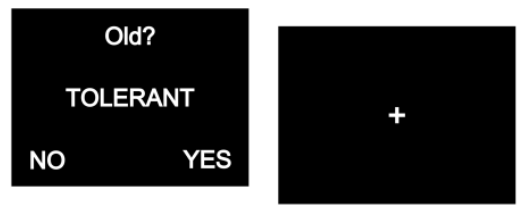
Fig. 1. Illustration of the memory task. The incidental encoding phasewas divided into two parts, each lasting roughly7 minutes, during which participants had to determine whether the adjective displayeddescribed them(self-referential condition) or a celebrity (other-referential condition), or whether it was a positive adjective or not (semantic condition). Adjectives weredisplayed on a screen one at a time for $3500 \mathrm{~ms}$, followed by a fixation cross for1000-3000 ms.Participants answered"Yes" or "No" with their right and left index fingers (counterbalanced across participants) using keypads. They were reminded of which side corresponded to which answer at the bottom of the screen. The recognition phase came immediatelyafter the incidental encoding session. Previously encountered adjectives (old ones) were mixed with distractors (new ones). Presentation of the adjectiveswas similar to that of the previous session (adjectives were presented on a screen one at a time for 3500 ms).Participants had to decide whether or not they had already seen each adjective during the incidental encoding session.

\subsection{Identity valence questionnaire}

All participants were asked to complete a questionnaire on identity valence.The questionnaire was always completed a few days after the memory task, as it involved referring to personality trait adjectives and it could have led to interference, for which aMCI and AD patients are particularly sensitive to.

This questionnairewas inspired by the second edition of the Tennessee Self-Concept Scale (TSCS2; Fitts\&Waren, 1996), the Questionnaire of Self-Representation (QSR; Duval et al., 2012), the revised version of the Self-Consciousness Scale(SCS-R; Scheier \& Carver, 1985), and the Self-Concept Clarity Scale (Campbell et al., 1996), and is suitable for patients with dementia. The questionnaire is mainly based on the TSCS2, which measures three components of the self-concept (identity, behavior, and self-satisfaction) in five different selfconcept domains (moral-ethical, social, personal, physical, and family). A further four self- 
concept domains are involved: two from the QSR (cognition and emotion), one from the SCS$\mathrm{R}$ (private self-consciousness), and one from the SCCS (flexibility/stability), resulting in nine self-concept domains. Respondents have torate50 self-descriptive statements:30 correspond to the five self-concept domains of the TSCS2, 12 to the two domains of the QSR, four to the domain of the SCS-R, and fourto the domain of the SCCS.

All the self-descriptive statements are affirmative, but 24 are positive (e.g., "I am a friendly, likeable person") and 26are negative (e.g., "I lack self-confidence"). Participants haveto determine whether or not each statement describesthem. The total score (identity valence score, 150) reflectsparticipants' overall sense of identity and associated level of selfesteem. A high score indicatesthat participants tend to hold a generally positive self-view, whereas a low score indicatesthat participants tend to hold a generally negative self-view.

An abridgedversion of this questionnaire had already been administered topatientswith AD in more severe stages of dementia(Eustache et al., 2013).

\subsection{Statistical analyses}

We ran one-way analyses of variance (ANOVAs), with Group as between-participants factor, on demographic and clinical characteristics, and a chi-square test on sex distribution.

Non parametric analyses (Mann-Whitney U tests) were performed on demographic and clinical characteristics to compare the two groups of patients with mild $\mathrm{AD}$ (the group that was able to perform the self-referential memory task and the one that was unable to perform it).

For the memory task, the total rates of hits and false alarmswere first calculated by group and then by group and valence, so as to assess participants' overall performance. Accuracy scores (proportion of hits minus proportion of false alarms) were then calculated by group, condition and valence, resulting in the following six scores: self negative accuracy, self 
positive accuracy, other negative accuracy, other positive accuracy, semantic negative accuracy and semantic positive accuracy.

Overall memoryscores were submitted to a Group (HC vs. aMCIvs. AD) xValence (positive vs. negative) analysis of covariance (ANCOVA), with the MADRS score as a covariate.

Owing to floor effects, the accuracy scores of the patients with AD by condition and valence were not included in subsequent analyses.

Accuracy scores were analyzed with a Group (HC vs. aMCI) x Condition (Self vs. Other and Self vs. Semantic) x Valence (positive vs. negative) ANCOVA, with the MADRS score as a covariate. ANOVAs and ANCOVAs were followed by posthoc analyses (Tukey's HSD test) whereappropriate.

Identity valence z-scores were computed in aMCI patients on the basis of the data of the $\mathrm{HC}$, such that negative $\mathrm{z}$-scores reflected relatively negative identity valence while positive z-scores reflected relatively positive identity valence. These scores were subjected to one-sample t-tests with 0 as a reference value.

Partial correlation coefficients betweenidentity valencez-scoresand the self accuracyscores (positive/negative) were then calculated for patients with aMCI, using MADRS as a continued predictor.Finally, in the aMCI group,we looked for significant correlations between the self accuracy scores (positive/negative) and the MMSE, MDRS,and MADRS.

All the statistical analyses were performed using STATISTICA software (StatSoft ${ }_{\text {, }}$ Tulsa, OK, USA). 


\section{Results}

\subsection{Demographic and clinical characteristics}

Table 1 illustrates the demographic and clinical characteristics of theparticipants and of the group of patients with mild $\mathrm{AD}$ that was unable to perform the self-referential memory task.

Regarding the participants, all three groups had similar sex distributions, $\chi^{2}(2)=.72, p$ $=.70$, and did not differ on age, $F(2,47)=2.05, p=.14, \eta_{\mathrm{p}}^{2}=.08$, or years ofeducation, $F(2,47)$ $=1.40, p=.26, \eta_{\mathrm{p}}^{2}=.07$. Between-group comparisons revealed similar sex distributionsThe analyses of MMSE scores revealed a main effect of Group, $F(2,47)=38.70, p<.001, \eta_{\mathrm{p}}^{2}=.62$. Posthoc analyses showedthat both patient groups had lower scores than $\mathrm{HC}(p s<.001)$, and patients with mild AD scored lower than patients with aMCI $(p<.001)$. In the same vein, there was a main effect of Group for MDRS scores, $F(2,47)=45.45, p<.001, \eta_{\mathrm{p}}^{2}=.66$, with both patient groups scoring lower than $\mathrm{HC}(p s<.001)$, and patients with mild AD scoring lower than aMCIpatients $(p<.001)$.The analysesof MADRS scores indicated a main effect of Group $F(2,47)=8.84, p<.001, \eta_{\mathrm{p}}^{2}=.27$. Patients withmildAD scored higher (reflecting greater depressive symptoms) on the MADRS than patients with aMCI $(p<.05)$ and $\mathrm{HC}(p<$ $.001)$, but there was no statistical significance between patients with aMCI and HC ( $p$ > .10).Regarding thecomparison of AD patients able and unable to perform the self-referential memory task, the analyses revealed that both groups had similar sex distribution, age and years of education. In addition, the two samples did not differ on MMSE, MDRS and MADRS. 
Table 1.

Demographic and clinical characteristics of the participants and the patients with mild $\mathrm{AD}$ unable to perform the self-referential memory task.

\begin{tabular}{|c|c|c|c|c|}
\hline & $\mathrm{HC}$ & $\mathrm{aMCI}$ & $\mathrm{AD}$ & $\begin{array}{l}\text { AD not } \\
\text { investigated for } \\
\text { SRE }\end{array}$ \\
\hline$n(\mathrm{M} / \mathrm{F})$ & $11 / 9$ & $9 / 11$ & $6 / 4$ & $6 / 4$ \\
\hline Age (years) & $71.60(5.25)$ & 74.15 (6.30) & $69.10(9.27)$ & $71.80(12.86)$ \\
\hline Education (years) & $11.15(3.22)$ & $9.70(3.16)$ & $11.70(4.52)$ & $9.70(1.49)$ \\
\hline MMSE score & $29.00(1.00)$ & $26.70^{\mathrm{a}}(1.22)$ & $23.80^{\mathrm{a}, \mathrm{b}}(2.70)$ & $21.60(3.34)$ \\
\hline MDRS score & $142.10(1.86)$ & $133.60^{\mathrm{a}}(4.57)$ & $122,00^{\mathrm{a}, \mathrm{b}}(10.27)$ & $118.10(10.77)$ \\
\hline MADRS score & $0.45(1.00)$ & $1.60(1.93)$ & $3.60^{\mathrm{c}}(3.10)$ & $4.50(3.06)$ \\
\hline \multirow{2}{*}{\multicolumn{5}{|c|}{$\begin{array}{l}\text { Note. } \text { Values are means (standard deviations). } \mathrm{HC}=\text { healthy controls; aMCI = amnestic mild } \\
\text { cognitive impairment; } \mathrm{AD}=\text { Alzheimer's disease; } n=\text { sample size; } \mathrm{M}=\text { male; } \mathrm{F}=\text { female; } \\
\text { MMSE = Mini Mental State Examination; MDRS = Mattis Dementia Rating Scale; MADRS }\end{array}$}} \\
\hline & & & & \\
\hline \multicolumn{5}{|c|}{ indicated a significant difference between a) $\mathrm{HC}$ and patients (aMCI and ADable to perform } \\
\hline \multicolumn{5}{|c|}{ the self-referential memory task), b) patients with aMCI and ADable to perform the self- } \\
\hline referential memo & taskand c) $\mathrm{H}$ & nd patients witl & Dable to perform & he self-referentia \\
\hline
\end{tabular}




\subsection{Overall performance on the memory task}

During encoding, the rates of total responses were almost 100\% (99.9 \pm .4$)$ for $\mathrm{HC}$, $96 \%( \pm 14)$ for patients with aMCI and 95\% ( \pm 6$)$ for patients with mild AD. During recognition, those rates were $100 \%( \pm .2)$ for $\mathrm{HC}, 99 \%( \pm 1.6)$ for patients with aMCI and 96 $\%( \pm 4.5)$ for patients with mild $\mathrm{AD}$. Besides, total mean response latencies during incidental encoding were $2000( \pm 317) \mathrm{ms}$ in the HC group, $2308( \pm 278) \mathrm{ms}$ in the aMCI group and 2404 $( \pm 144) m s$ in the AD group.

Table 2 sets out the overall performances of the participants on the memory task (i.e., proportions of hits and false alarms) first as a function of group, then as a function of group and adjective valence. Regarding total hit rates, the analysis revealed a main effect of Group $F(2,46)=5.21, p<.009, \eta_{\mathrm{p}}^{2}=.18$. Posthocanalyses indicated a significant difference between $\mathrm{HC}$ and patients withaMCI (HC had higher total hit rates than patients with aMCI, $p<.05$ ), but neither between patients with aMCI and mild $\mathrm{AD}(p=.72)$ nor, paradoxically, between HC and patients with mildAD $(p=.26)$. The patients with mild AD tended to answer "yes" most of the time, resulting in apparently preserved recognition. Regarding total false alarm rates, there was no main effect of Group $F(2,46)=.73, p=.50, \eta^{2}{ }_{\mathrm{p}}=.03$.

The analysis of total hit rates as a function of Group and Valence showed a main effect of Group $F(2,46)=5.21, p<.009, \eta_{p}^{2}=.18$, a main effect of Valence $F(1,46)=41.01, p<$ $.001, \eta_{\mathrm{p}}^{2}=.47$, and a significant interaction between Group and Valence $F(2,46)=6.45, p<$ $.003, \eta_{\mathrm{p}}^{2}=.22$. Both patient groups had higher hit rates for positive adjectives than for negative ones $(p s<.001)$, whereas in the HC group, there was no difference in hit rates betweenvalences $(p=.13)$. In addition, the proportion of hit rates for negative adjectives was significantly lower in both patient groups(aMCI and mild AD) compared with $\mathrm{HC}(p s<.005)$, whereas the proportion of hit rates for positive adjectives did not differbetween the three groups $(p s>.84)$. Analysis of total false alarm rates as a function of Group and Valence 
showed no effect of $\operatorname{Group} F(2,46)=.75, p=.48, \eta_{p}^{2}=.03$, but there was a main effect of Valence $F(1,46)=44.13, p<.001, \eta_{p}^{2}=.49$, and a significant Groupx Valence interaction effect, $F(2,46)=3.37, p<.05, \eta_{p}^{2}=.13$. The patients with mild AD producedsignificantly more false alarms for positive distractors than HC $(p<.002)$, but not the patients with aMCI $(p$ $=.48$ ). Within the groups, there were more false alarms for positive than for negative distractors $(\mathrm{HC}, p<.01$; patients with aMCI and $\mathrm{AD}, p s<.001)$.

In the following section, we set out the accuracy scores, which we calculated by subtracting false alarms from total hits. The accuracy scores by condition and valence of the patients with mild $\mathrm{AD}$ were extremely low, sometimes resulting in a floor effect. For this reason, the patients with mildAD were excluded from subsequent analyses. Nonetheless, to go deeper into the analyses of the AD group, we examined individuals' profile of SRE in the 10 patients that had performed the task. Individuals' SRE above 5\% were considered as a significant benefit for self-referential information. For positive adjectives, seven(SRE rangingfrom 5 to $33 \%$ ) and five (SRE ranging from 5 to $11 \%$ ) patients showed a significant benefit in the self-referential condition compared respectively to the semantic and the other ones, while for negative adjectives, only two and three patients showed a significant SRE. In addition, for the negative adjectives, six and seven patients showed negatives effects, i.e. a significant difference with lower performances in the self-referential condition compared to the semantic and the other ones, respectively. 
Table 2.

Overall performance of $\mathrm{HC}$, patients with aMCI and mild AD on the memory task.

\begin{tabular}{llll}
\hline Total & HC & aMCI & AD \\
\hline Hits & $.64(.13)$ & $.52(.15)$ & $.56(.10)$ \\
Negative hits & $.59(.15)$ & $.40(.20)$ & $.35(.19)$ \\
Positive hits & $.69(.14)$ & $.63(.15)$ & $.76(.12)$ \\
FA & $.31(.15)$ & $.34(.15)$ & $.45(.10)$ \\
Negative FA & $.24(.15)$ & $.21(.19)$ & $.65(.16)$ \\
Positive FA & $.39(.19)$ & $.48(.16)$ & \\
\hline
\end{tabular}

Note. Mean(standard deviation) overall performance (expressed as aproportion of total items) on the memory task for the three groups. See Results section3.2 for significant differences. $\mathrm{FA}=$ false alarms

\subsection{Influence of adjective valence on the SRE in patients with aMCI and HC}

Analysis of accuracy scores revealed main effects of Group $F(1,37)=15.23, p<.001$, $\eta_{p}^{2}=.29$, andCondition, $F(2,74)=19.41, p<.001, \eta_{p}^{2}=.34$, but notof Valence, $F(1,37)=$ 2.70, $p=.11, \eta_{p}^{2}=.07$. There were no significant interactions between either Groupand Condition $F(2,74)=1,00, p=.38, \eta_{p}^{2}=.03$, or Groupand Valence $F(1,37)=.06, p=.80, \eta_{p}^{2}=$ .00 , whereas the Condition $\mathrm{x}$ Valence interaction was significant, $F(2,74)=3.46, p<.05, \eta_{p}^{2}=$ .09. Finally, theinteraction between Group, Condition and Valence was significant, $F(2,74)=$ 3.22, $p<.05, \eta^{2}=.09$ (Fig.2).Posthoc analyses revealed a significant difference between HC and patients with aMCI on the self negative accuracy score. Patients with aMCIhad a lower self negative accuracy score than $\mathrm{HC}(p<.02)$. All other between-group differences were 
nonsignificant (self positive accuracy, $p=.25$; other negative accuracy, $p=.24$; other positive accuracy, $p=.42$; semantic negative accuracy, $p=.78$; semantic positive accuracy, $p=.22$ ).

For HC,theself negative accuracy scorewas higher than both the other negative accuracy score $(p<.05)$ and the semantic negative accuracy score $(p<.001)$. Theirself positive accuracy score was also higher than both their other positive accuracy score $(p<.01)$ and their semantic positive accuracy score $(p<.05)$. By contrast, the patients with aMCI had equivalent negative accuracy scores (self negative accuracy vs. other negative accuracy and self negative accuracy vs. semantic negative accuracy, $p=.86$ and $p=.61$, respectively). However, like HC, theirself positive accuracy scorewas higher than both the other positive accuracy score $(p<.05)$ and the semantic positive accuracy score $(p<.05)$. All other differences were nonsignificant.

Hence, regardless of the controlcondition (other or semantic), HC exhibited an SRE for both negative and positive adjectives, whereasin the aMCI group, the SRE was only significant for positive adjectives. The absence of an SRE in patients with aMCI for negative adjectives seemed to be due to their less accurate recognition of self-referentially encoded negative adjectives compared with HC. 


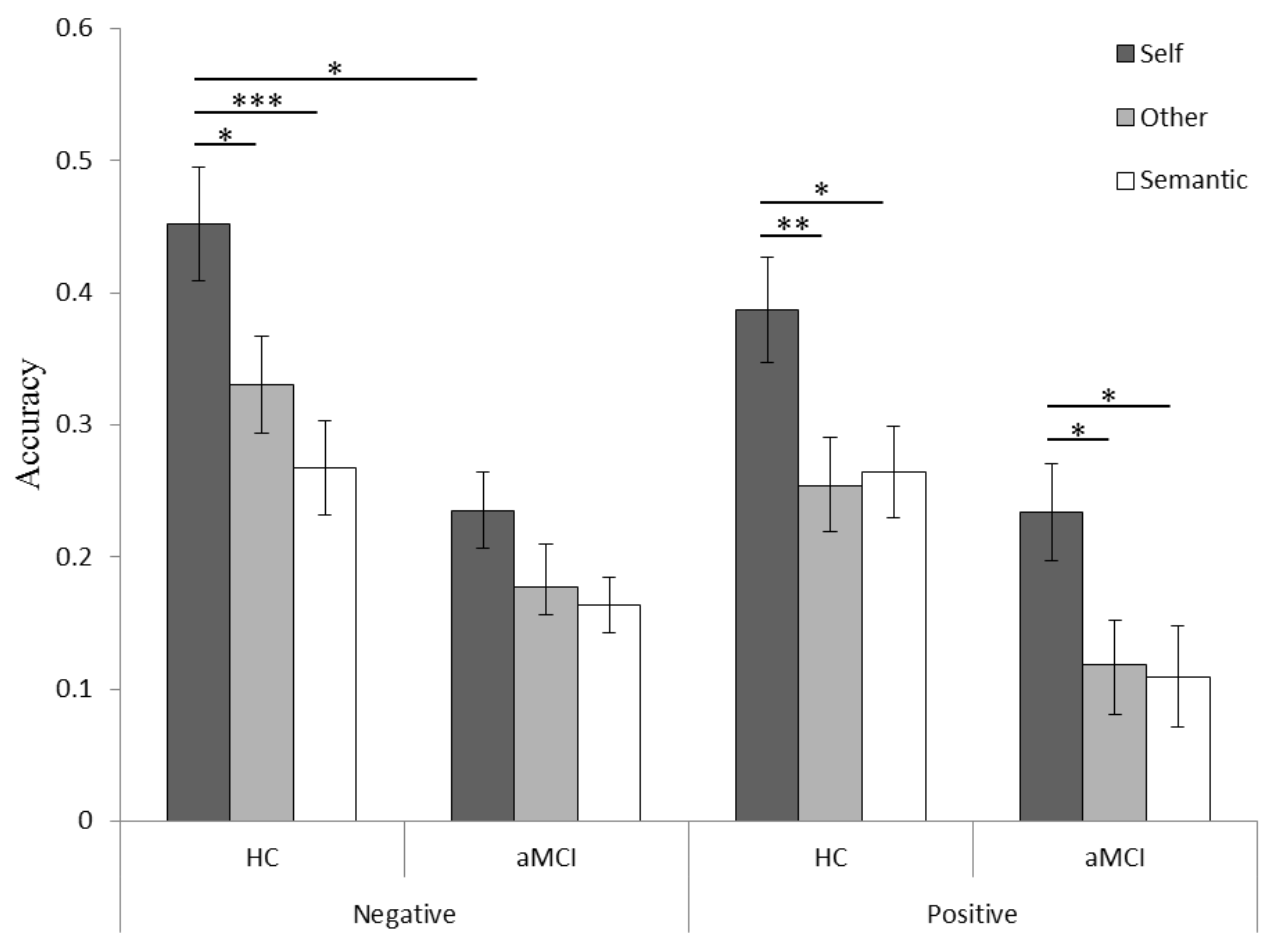

Fig. 2.Mean accuracy scores (proportion of hits minus proportion of false alarms) for negative and positive adjectives encoded with reference to the self or a distant other,or processed semantically,for $\mathrm{HC}$ and patients with aMCI. Error bars indicate standard errors of the mean (SEMs). $* p<.05 . * * p<.01 . * * * p<.001$.

3.4.Identity valence inHC,patients with aMCIand mild $A D$, and its effect on the SRE inpatients with aMCI.

The mean $( \pm S D)$ identity valence $\mathrm{z}$-scores were $-.50 \pm .87$ for patients with aMCI and$.46 \pm .72$ for patients with mild AD.The analyses revealed that patients with mild ADheld relativelypositive self-representations when compared with $\mathrm{HC}, t=1.57, p=.18$. However, patients with aMCIheld relatively negative self-representations when compared withHC, $t=$ $2.45, p<.05$. It should be noted that the identity valence scores of two patients with aMCI and four patients with mildAD were missing, either because the patients refused to complete the questionnaire, or because they did not understand the instructions. 
Identity valence z-scores and self (positive/negative) accuracy scores of patients with aMCI were subjected to partial correlations with MADRS as a continued predictor.There was a significant positive correlation between negative identity valence z-scores and the self negative accuracy scores $(r=.52, p<.05)$, but the correlation between positiveidentity valence $\mathrm{z}$-scores and the self positive accuracy scores was not significant $(r=.28, p=.26)$.

\subsection{Relationship between the SRE and dementia severity/depressivesymptoms in patients with aMCI.}

Supplemental correlation analyses between the two self accuracy scores (negative/positive) and the MMSE, MDRS andMADRS were carried out in patients with aMCIto investigate the effectsof cognitive deficit severityand depressive symptoms. No significant correlation was found.

Therefore, neither cognitive deficits,nor depressive symptoms appeared to be linked to the loss of the SRE for negative adjectives and its preservation for positive adjectives in patients with aMCI.

\section{DISCUSSION}

The main purpose of this study was to shed light on the mechanisms that may allowthe SRE on episodic memoryto persist across the early stages of AD pathology (aMCI probably due to $\mathrm{AD}$ and mild $\mathrm{AD}$ ). Only one previous studyinvestigatingthis issue had includedpatients with aMCI, but the focus was not on the SRE per se (Rosa, Deason, Budson, \& Gutchess, 2015).Furthermore, thefew studies exploring this issue in patientswith AD had reported heterogeneous results: the SRE was either absent (Genon et al., 2014; Lalanne et al., 2013) or present and independent fromthe valence of the material used (Kalenzaga et al., 2013).Additionally, the SRRE had been foundeither absent (Genon et al., 2014) or present, but inherent to the emotional aspects of the material used. In AD, Lalanneet al. (2013) 
foundthat the SRRE only appearedfor positive adjectives, while Kalenzaga and Clarys (2013) and Kalenzaga et al. (2013) only observed the SRRE for negative adjectives.In the present study, we investigated the influence of the valence of encoding material (adjectives) on the expression of the SRE in healthy older individuals,patients with aMCIand patients with mild AD. In addition, we looked at the extent to which the valence of our participants' identity modulated the SRE.

The memory task had recently been validated by our laboratory in a larger sample of healthy young individuals(Morel et al., 2014), and in the present study, we showed it to be appropriate and sensitive for the study of the SRE in both healthy older individuals and patients with aMCI. However, the memory task appeared too difficult for AD patients. This limitation will be discussed later. We showed that the SRE was present in healthy old individuals independently of material valence (positive or negative adjectives) and control condition (other or semantic). By contrast, in patients with aMCI, the SRE only manifested itself for positive adjectives, regardless of the control condition (other or semantic).The absence of an SRE for negative adjectives in these patients correlated with the degree to which they perceived themselves negatively.

The beneficial effect of self-referential processing on episodic memory reported here for healthy older individuals corroborates results from previous studies inhealthy aging (Gutchess, Kensinger, \& Schacter, 2010). The emotional independence of the SRE in healthy aging has also been reported elsewhere (Glisky \& Marquine, 2009; Gutchess et al., 2007; Mueller et al., 1986), in particular when recognition is corrected by false alarms. As in the present study, both Gutchess et al. (2007) andGlisky and Marquine (2009) reportedsignificantly higher false alarm rates for positive distractors than for negative ones in healthy older participants. We observed thatthe amplitude of the SRE in our sample of healthy older individuals was not greater for positive stimuli than for negative ones. The positivity 
effect, defined as an age-related trend to attend to-and remember-stimuli that are positive rather than negative, has been well documented (see Reed \& Carstensen, 2012, for a review). As people age, time horizons are increasingly perceived of as being constrained. According to the socioemotional selectivity theory (Carstensen, 2006), this change in the subjective sense of time left to live leads to a reorganization of the goal hierarchy, with the regulation of emotions becoming a priority. Immediate emotional gratification and wellbeing become more important than other type of goals involving delayed rewards.

aMCI patients from the present study showed a SRE which magnitudewas similar to that of our healthy old participants when the adjectives were positive, but this effect disappeared when the adjectives were negative. Interestingly, a quite important proportion of patients with mild AD showed this pattern, as revealed by complementary analyses we made on individual's profile. As expected, the overall memory performance of the patients with aMCI was lower than that of healthy old participants, indicating that the SRE for positive adjectives was not strong enough to counteract their memory impairments. All in all, these patients demonstrated a positivity effect for total hits, as well as a positivity bias for false alarms. Because the SRE persisted among the patients with aMCI for positive adjectives, it can be argued that these patients benefited from a positivity effect for self-referred information. This result was neither related to dementia severity, nor to depressive symptoms, even though the patients with aMCI were more impaired on these cognitive aspects than healthy old participants. Moreover,aMCI patients rated their identity relatively more negativelythan healthy old participants, a result that we did not expect, since it had been reported in previous studies that $\mathrm{AD}$ patients exhibited a relatively positive sense of identity when compared with healthy old individuals (Eustache et al., 2013; Kalenzaga \& Clarys, 2013; Lalanne et al., 2013). This could be attributed to the fact that some AD patients from the present study were anosognosic, as recently reported by our laboratory(Perrotin et al., 
2015). In particular, Perrotin et al. (2015) have demonstrated that the lack of awareness of memory disorders in these AD patients was due to disconnection between and within selfrelated and memory-related brain networks.Contrary to $\mathrm{AD}$ patients from the present study,patients with aMCI were more aware of their cognitive deficits, which may have had an impact on the way they perceived themselves (i.e., more negatively than patients with mild AD). We said above that the absence of an SRE for negative adjectives wasrelated to the extent to which some patients held a generally negative view of themselves. Indeed, the loss of an SRE for negative adjectives stemmed not from ageneral decline in the recognition of these adjectives, but from a specific decrease in the recognition of negative adjectives processed with reference to the self. In addition, recognition performancefor negative adjectives processed with reference to the selfmatchedthose of negative adjectives encoded with reference to another person or processed semantically. Several hypotheses can thus be formulated: either negative adjectives were not processed self-referentially at the time of encoding, or if they were, they did not undergo the appropriate depth of processing. Another hypothesis is that, at the time of recognition, negative adjectives that had previously been selfreferred were ignored.

According to Conway's self-memory system(Conway, 2005), the working self and the autobiographical memory knowledge base lie at the root of the relationship between self and memory. The working self is an executive identity driven by goals. It allows for the encoding of information in accordance with the individual's goals, while at the same time maintaining a coherent representation of the interactions between the self and its environment, thus providing a continuous feeling of identity. The working self may control the encoding and retrieval of information in and from the autobiographical knowledge base. It thus fulfils two functions: executive (goal-directed) and conceptual (subjective self-representation).In studies using self-reference paradigms where a free-recall task was administered instead of a 
recognition task, healthy individuals exhibited a positivity effect for self-referential information (Kuiper \& Derry, 1982; Sanz, 1996;Sedikides \& Green, 2000). However, in a free-recalltask, participants are providedwithfewerretrievalcuesthantheywouldbe in a recognition task, wherecues are providedalongwithlures. As such, in a free-recall task, participants need more to elaborate their own retrieval cues, in order to gain access tostored information (Koutstaal\&Schacter, 1997). D’Argembeau, Comblain, and Van der Linden (2005) investigated whether this positivity effect for self-referential information depends on retrieval conditions, by comparing the memory performances of healthy individuals on freerecall versus recognition tasks. They observed a positivity effect for self-referential adjectives in the free-recall task, but no effect of valence for self-referential adjectives in the recognition task. The authors concluded that the positivity effect observed in the free-recall task probably emerged because of the control over access to stored information exerted by the working self,with the latter shaping appropriate retrieval cues for accessing memories relevant to the individuals' current goals. By contrast, in the recognition task (like the one in the present study), where individuals hadless need to elaborate retrieval cues, the working self had less control over access to stored information.Kalenzaga and Clarys (2013) also explored the impairment of both components of the working self (i.e., executive and conceptual) in patients with AD. They demonstrated that although these patients rated their personality as positively as healthy older individuals did, they exhibited a negativity effect for self-referential adjectives. The authors therefore hypothesized that self-related information may be processed differentially, depending on the level of consciousness required by the task. They postulated that explicitly self-related information (e.g., in self-rating questionnaires) is processed in a controlled way, whereas implicitly self-related information (e.g., in self-reference encoding) is processed in an automatic way. This hypothesis is in line with D'Argembeau et al. (2005)'s results set out above.Unlike the patients with AD in Kalenzaga and Clarys (2013)'s study, our 
patients with aMCI had a relatively negative explicit view of themselves, but exhibited a positivity effect for self-referential adjectives that were supposedly processed automatically. Here, we suggest that this process may actually have beencontrolled, rather than automatic. Even though the patients with aMCI were performing a recognition task, their working selvesmay have had an opportunity to exert their control over which information should be encoded and retrieved, and which should be omitted. This controlled processing of information may serve as a defense mechanism in the presence of potential threats to the preservation of the self. AD patients fromKalenzaga and Clarys (2013) study lived in a nursing home. The authors indeed reported that AD patients informants (caregivers from the nursing home) were prone to rate the patients' personalities and autonomy more negatively than that of healthy older individuals institutionalized in the same nursing home. By contrast, aMCI patients from our study were, by definition and in facts, autonomous, living in the dwelling community and engaged in healthy social activities. Because a loss of self is often linked to the disease (Herskovits, 1995), AD usually conveys fear among the general population. Many studies have shown that social interactions influence the way that patients with AD experience their selves (Harman \& Clare, 2006; Katsuno, 2005;Kitwood \& Bredin, 1992; Langdon, Eagle, \& Warner, 2007). In AD, detrimental interpersonal relationships with others have been shown to be a potential threat for the self, while healthy social interactions have been shown to be beneficial for the integrity and maintenance of a sense of self, as well as for self-esteem (Sabat \& Harré, 1992; Sørensen, Waldorff, \& Waldemar, 2008).

Three studies had previously used a memory task similar to ours to investigate the SRE in AD. Only in Genon et al. (2014)'s study had the task been administered-as it was in the present study-to healthy older individuals and patients with AD inside a 3T MRI scanner. The patients with AD in Genon et al. (2014)'s study were at the same, early-mid stage of dementia as ours. Encoding was also incidental, and the SRE was calculated in the same way 
as in the present study. However, there was only one control condition (other), and the effect of material valence was not investigated. The authors reported an SRE in the group of healthy older individuals, corroborating our results. In addition, they failed to find an SRE in the AD group. Patients' recognition performance for adjectives encoded with reference either to self or to other weregenerally lower than those of healthy older individuals, but there was no floor effect. Moreover, the percentage of correct rejections of new items (which inversely reflects false alarms) was relatively high in the AD group (77.6 \pm 12.6$)$, albeit statistically below that of the group of healthy older individuals $(89.2 \pm 5.9)$. There are severalmethodological reasons why the SRE could be investigated in the patients with AD in Genon et al. (2014)'s study. First of all, the patient sample was larger than ours (21 vs. 10), which may have contributed to better data collection and statistical robustness. Second, unlike our sample of patients who were not receiving any treatment, twelve patients were receiving an anticholinesterase inhibitor and five patients were taking Ginkgo biloba during the experiment. Those two treatments are known to potentially decrease or decelerate memory loss in AD (Diamond \& Bailey, 2013; Song et al., 2014). We cannot totally exclude the possibility that this variable contributed to the fairly good overall recognition performance of the patients with AD in Genon et al. (2014)'s study. Third and last, the memory task was administered in a different way. The patients with AD in Genon et al. (2014)'s study underwent more intensive pre-experimental training. In addition, the encoding session was intentional (participants knew a recognition session would follow). Once again, these two variables may have promoted deeper encoding, leading to better-and usable-recognition performance data (Craik \& Lockhart, 1972). Like us, Lalanneet al. (2013) used a memory task in which encoding was incidental, although there was only one control condition (semantic). They applied Cohen's $d$ to calculate the memory performances of healthy older individuals and patients with AD.As in the present study, they found an SRE in healthy olderparticipants 
that was independent of material valence.As indicated above, they failed to find an SRE in the AD group. Cohen's $d$ is an effect size, usually used in meta-analyses, and it reflects the difference between two means divided by the standard deviation of the data. The higher its value, the larger the effect size. With this method of calculation,Lalanne et al. (2013) reported that healthy older participants displayed dramaticallybetter recognition performances than the patients with $\mathrm{AD}$, in bothsemantic and self conditions. This observation raises the question of whether the SRE could actually be investigated in the AD group, asthe patients' memory performancesin each condition were so low that they leftthe data open to misinterpretation. It should be noted that the patients with AD in Lalanne et al. (2013)'s study were at the same mild stage of dementia as the patients in the present study. Finally, Kalenzaga et al. (2013) applied an intentional memory task with a self-reference and a semantic condition to patients with $\mathrm{AD}$ who were at a more pronounced stage of dementia than the patients in the present study. Both groups (patients and healthy older individuals) were recruited from nursing homes. The patients were able to perform the memory task despite the severity of their disease. The study reported an overall decline in recognition performances among patients, compared with control participants. However, the patients with AD benefited just as much from the SRE as the healthy older participants, regardless of the valence of the material (positive or negative adjectives). These conflicting results may once again stem from a methodological issue, asKalenzaga et al. (2013) did notcorrect recognition performances for false alarms. As demonstrated in many studies(including the present one), the omission of false alarms in the estimation of recognition performance can lead to a misinterpretation of the data.

Up to now, the effect of material valence on the expression of the SRRE in AD has only been investigated and reported in three studies. Looking at the effect of self-reference through the $\mathrm{R} / \mathrm{K}$ paradigm is another, more concise, way of estimating the SRRE on episodic 
memory performance, as the $\mathrm{R} / \mathrm{K}$ paradigm makes it possible to distinguish between correct responses according to the underlying memory process (episodic/semantic). In patients with AD, the SRRE has variously been shown to be salient for negative (Kalenzaga\&Clarys, 2013, Kalenzaga et al., 2013) and for positive (Lalanne et al., 2013) adjectives. Once again, these conflicting results may stem from differences in methodological approach: the patients in Kalenzaga and Clarys (2013) and Kalenzaga et al. (2013)'s studies were at a more pronounced stage of the disease, and were institutionalized in nursing homes, whereas those in Lalanne et al. (2013)'s study were not.

One limitation to this study was the setting of the memory task. We are aware that the MRI scanner could have been a stressful environment for patients withmild AD and haveconstituteda major obstacle to collect data in this group. However, some patients with mild AD already had troubles to perform the pre-experimental, training session, outside the scanner.A second limitation was the overall difficulty of the self-reference task for the patientswith mild AD. Another one, directly related to this first limitation, was the small sample size of AD patients that could be investigated, which probably reduced the robustness of our statistical analysis. Ten of the 20 patients initially recruited in the study had to be excluded because they could not understand the instructions of the memory task. However, as shown in Table 1, the sample of AD patients excluded presented a neuropsychological profile similarto the one included. For instance, both sample were at the mild stage of Alzheimer's disease with regard to their mean MMSE score (between the range of 19 to 24 ;Feldman \& Woodward, 2005). However, their cognitive impairments were quantitatively more pronounced, even though these observations were not statistically significant. Thus, precautions must be taken, probably at the time of the neuropsychological screening and before any inclusion in a study, whenattempting to study complex memory processes in AD 
patients.We hope these results will serve future investigations on the $\mathrm{SRE}$ in $\mathrm{AD}$, by saving time and possible inconvenience for the investigators, and above all, for the patients.

Finally, with regard to the sample of patients with mild ADwho performed the selfreferential memory task, we were able to observe that they rated their personality just as positively as patients with aMCI and healthy older individuals. This result corroborates the findings of previous studies showing that patients with $\mathrm{AD}$ tend to rate their personality as positively as healthy older individuals do (Kalenzaga\&Clarys, 2013; Lalanne et al., 2013), even when they are in the more severe stages of the disease (Eustache et al., 2013).Moreover, the patients with mild $\mathrm{AD}$ performed the task appropriately, as revealed by the rates of total responses and mean response latencies during encoding and recognition. They recognized significantly more positive adjectives than negative ones overall and produced more false alarms for positive adjectives than healthy older individuals.Interestingly, complementary analyses revealed that a quite important proportion of $\mathrm{AD}$ patients displayed a SRE for positive adjectives. Because patients with mild $\mathrm{AD}$ have severe episodic memory impairments, their attention bias toward positive information probably failed to counteract their memory deficits. The positivity effect observed in aging may therefore persist, but be altered in AD patients. However, we cannot exclude the possibility that these observations could be an epiphenomenon of a small sample. Of note, nonparametric analyses yielded similar results.

\section{CONCLUSIONS}

To conclude,we investigated and reported for the first time a SRE for positive personality trait adjectives in patients with aMCI. The finding that patients with aMCI who heldnegative self-representations systematically failed to recognize negative selfreferentialadjectives,but successfully recognized the positive ones,points to a controlled processing of informationaimed at regulating emotions and wellbeing. This controlled 
processing of information may reflect some sort of self-defense, or mnenic neglect, as suggested by Sedikides and Green (2000, 2004). Theirmnenic neglect modelstates that feedback that is negative for central self-aspectsisself-threatening. It triggersa self-defense mechanism wherebynegative information related to the self is poorly recalled, compared with negative information related to another person (Sedikides \& Green, 2000, 2004). Most importantly, with regard to anosognosiathat is sometimes encountered in $\mathrm{AD}$, it appears to be information negativity, rather than information inconsistency (with the self), that drivesmnenic neglect.Sedikides and Green (2004) had shown that healthy participants holding negative self-representations recalled positive feedback better than negative ones, which is the pattern we observed during recognition in our sample of aMCI patients. It seems as if threat to the self would build over other factorsfor maintaining a positive self-esteem via positive selfrelated memories.

More investigations are needed to pinpoint the exact moment at which mnenic neglect may occur. Either self-negative information is allocated fewer resources and processed more shallowly than self-positive information during encoding, self-negative information is blocked at retrieval, or both.Finally, if mnenic neglect sometime fails to operate in patients with AD (Kalenzaga\&Clarys, 2013;Kalenzaga et al., 2013),it may be because of the negative, institutionalized setting in which some of themlive, and the negative feedback they receive from it. It is therefore of the utmost importance tofocus on patients' psychosocial, affective dimension, as it may constitute an important factor forthe preservation of the self-and memory-in AD pathology.

\section{Acknowledgements}

This research was supported by grants from EcolePratique des Hautes Etudes (EPHE, Paris), theFrench Hospital Program for Clinical Research (PHRC National 2012), the nonprofit organization Fondation Plan Alzheimer, Lower Normandy Regional Council, and 
the French National Institute for Health and Medical Research (INSERM). The authors declare no conflicts of interest. We would like to thank N. Villain for his contribution in the design of the task. We would also like to thank S. Benbrika, R. de Flores, F. Dégeilh, M. Gaubert, J. Gonneaud, F. Mézenge, J. Mutlu, A. Pélerin, A. Perrotin, A.Quillard, C. Schupp, C. Tomadesso,and the Cyceron MRI-PET staff members for their help with the patients and with data collection.We also are grateful to E. Portierfor having editing the manuscript in fluent academic English.

\section{REFERENCES}

Abrisqueta-Gomez, J., Bueno, O. F. A., Oliveira, M. G. M., \& Bertolucci, P. H. F. (2002). Recognition memory for emotional pictures in Alzheimer's patients. Acta Neurologica Scandinavica, 105(1), 51-54. doi:10.1034/j.1600-0404.2002.00035.x

Boller, F., El Massioui, F., Devouche, E., Traykov, L., Pomati, S., \& Starkstein, S. E. (2002). Processing emotional information in Alzheimer's disease: Effects on memory performance and neurophysiological correlates. Dementia and Geriatric Cognitive Disorders, 14(2), 104-112. doi:10.1159/00006493264932

Campbell, J. D., Trapnell, P. D., Heine, S. J., Katz, I. M., Lavallee, L. F., \& Lehman, D. R. (1996). Self-concept clarity: Measurement, personality correlates, and cultural boundaries. Journal of Personality and Social Psychology, 70(1), 141-156.

Carstensen, L. L. (2006). The influence of a sense of time on human development. Science,312(5782), 1913-1915. doi:10.1126/science.1127488

Chételat, G., Eustache, F., Viader, F., De La Sayette, V., Pélerin, A., Mézenge, F., ... Desgranges, B. (2005). FDG-PET measurement is more accurate than 
neuropsychological assessments to predict global cognitive deterioration in patients with mild cognitive impairment. Neurocase, 11(1), 14-25. doi:10.1080/13554790490896938

Conway, M. A. (2005). Memory and the self. Journal of Memory and Language, 53(4), 594628. doi:10.1016/j.jml.2005.08.005

Conway, M. A., Dewhurst, S. A., Pearson, N., \& Sapute, A. (2001). The self and recollection reconsidered: How a'failure to replicate'failed and why trace strength accounts of recollection are untenable. Applied Cognitive Psychology, 15(6), 673-686. doi:10.1002/acp.740

Craik, F. I. M., \& Lockhart, R. S. (1972). Levels of processing: A framework for memory research. Journal of Verbal Learning and Verbal Behavior, 11(6), 671-684. doi:10.1016/S0022-5371(72)80001-X

Craik, F. I. M., \& Tulving, E. (1975). Depth of processing and the retention of words in episodic memory. Journal of Experimental Psychology, 104(3), 268-294.

Crowell, T. A., Luis, C. A., Vanderploeg, R. D., Schinka, J. A., \& Mullan, M. (2002). Memory Patterns and Executive Functioning in Mild Cognitive Impairment and Alzheimer's Disease. Aging, Neuropsychology, and Cognition, 9(4), 288-297. Retrieved from http://www.tandfonline.com/doi/abs/10.1076/anec.9.4.288.8772

D'Argembeau, A., Comblain, C., \& Van der Linden, M. (2005). Affective valence and the self-reference effect: Influence of retrieval conditions. British Journal of Psychology96(Pt 4), 457-466. doi:10.1348/000712605X53218

Diamond, B. J., \& Bailey, M. R. (2013). Ginkgo biloba: Indications, mechanisms, and safety. The Psychiatric Clinics of North America, 36(1), 73-83. doi:10.1016/j.psc.2012.12.006 
Döhnel, K., Sommer, M., Ibach, B., Rothmayr, C., Meinhardt, J., \& Hajak, G. (2008). Neural correlates of emotional working memory in patients with mild cognitive impairment. Neuropsychologia, 46(1), 37-48. doi:10.1016/j.neuropsychologia.2007.08.012

Dulas, M. R., Newsome, R. N., \& Duarte, A. (2011). The effects of aging on ERP correlates of source memory retrieval for self-referential information. Brain Research, 1377, 84100. doi:10.1016/j.brainres.2010.12.087

Duval, C., Desgranges, B., de La Sayette, V., Belliard, S., Eustache, F., \& Piolino, P. (2012). What happens to personal identity when semantic knowledge degrades? A study of the self and autobiographical memory in semantic dementia. Neuropsychologia, 50(2), 254265. doi:10.1016/j.neuropsychologia.2011.11.019

Eustache, F., Desgranges, B., \& Lalevée, C. (1998). [Clinical evaluation of memory]. Revue Neurologique, 154 (Suppl 2, S18-32). $\quad$ Retrieved from http://www.ncbi.nlm.nih.gov/pubmed/9834542

Eustache, M.-L., Laisney, M., Juskenaite, A., Letortu, O., Platel, H., Eustache, F., \& Desgranges, B. (2013). Sense of identity in advanced Alzheimer's dementia: A cognitive dissociation between sameness and selfhood? Consciousness and Cognition, 22(4), 1456-1467. doi:10.1016/j.concog.2013.09.009

Feldman, H. H., \& Woodward, M. (2005). The staging and assessment of moderate to severe Alzheimer disease. Neurology, 65(Issue 6, Supplement 3), S10-S17. doi:10.1212/WNL.65.6_suppl_3.S10

Fitts, W. H., \& Warren, W. L. (1996). Tennesse self-concept scale: Manual. Los Angeles, CA: Western Psychological Services. 
Flicker, C., Ferris, S. H., \& Reisberg, B. (1991). Mild cognitive impairment in the elderly: predictors of dementia. Neurology, 41(7), 1006-9. Retrieved from http://www.ncbi.nlm.nih.gov/pubmed/2067629

Folstein, M. F., Folstein, S. E., \& McHugh, P. R. (1975). “Mini-mental state”. A practical method for grading the cognitive state of patients for the clinician. Journal of Psychiatric $\begin{array}{llll}\text { Research, } & \text { 12(3), } & \text { 189-198. } & \text { Retrieved }\end{array}$ http://www.ncbi.nlm.nih.gov/pubmed/1202204

Gardiner, J. M. (1988). Functional aspects of recollective experience. Memory \& Cognition, 16(4), 309-313. Retrieved from http://www.ncbi.nlm.nih.gov/pubmed/3210971

Gauthier, S., Reisberg, B., Zaudig, M., Petersen, R. C., Ritchie, K., Broich, K., ... Winblad, B. (2006). Mild cognitive impairment. Lancet, 367(9518), 1262-70. doi:10.1016/S01406736(06)68542-5

Genon, S., Bahri, M. A., Collette, F., Angel, L., d'Argembeau, A., Clarys, D., ... Bastin, C. (2014). Cognitive and neuroimaging evidence of impaired interaction between self and memory in Alzheimer's disease. Cortex, 51, 11-24. doi:10.1016/j.cortex.2013.06.009

Giffard, B., Laisney, M., Desgranges, B., \& Eustache, F. (2015). An exploration of the semantic network in Alzheimer's disease: Influence of emotion and concreteness of concepts. Cortex; a Journal Devoted to the Study of the Nervous System and Behavior, 69, 201-211. doi:10.1016/j.cortex.2015.05.020

Glisky, E. L., \& Marquine, M. J. (2009). Semantic and self-referential processing of positive and negative trait adjectives in older adults. Memory,17(2), 144-157. doi:10.1080/09658210802077405

Greenaway, M. C., Lacritz, L. H., Binegar, D., Weiner, M. F., Lipton, A., \& Munro Cullum, C. (2006). Patterns of verbal memory performance in mild cognitive impairment, 
Alzheimer disease, and normal aging. Cognitive and Behavioral Neurology: Official Journal of the Society for Behavioral and Cognitive Neurology, 19(2), 79-84. doi:10.1097/01.wnn.0000208290.57370.a3

Gutchess, A. H., Kensinger, E. A., Yoon, C., \& Schacter, D. L. (2007). Ageing and the selfreference effect in memory. Memory,15(8), 822-837. doi:10.1080/09658210701701394

Gutchess, A. H., Kensinger, E. A., \& Schacter, D. L. (2010). Functional neuroimaging of selfreferential encoding with age. Neuropsychologia, 48(1), 211-219. doi:10.1016/j.neuropsychologia.2009.09.006

Hamami, A., Serbun, S. J., \& Gutchess, A. H. (2011). Self-referencing enhances memory specificity with age. Psychology and Aging, 26(3), 636-646. doi:10.1037/a0022626

Harman, G., \& Clare, L. (2006). Illness representations and lived experience in early-stage dementia. Qualitative Health Research, 16(4), 484-502. doi:10.1177/1049732306286851

Herskovits, E. (1995). Struggling over subjectivity: Debates about the "self" and Alzheimer's disease. Medical Anthropology Quarterly, 9(2), 146-164. Retrieved from http://www.ncbi.nlm.nih.gov/pubmed/7671112

Irish, M., Lawlor, B. A., O’Mara, S. M., \& Coen, R. F. (2010). Exploring the recollective experience during autobiographical memory retrieval in amnestic mild cognitive impairment. Journal of the International Neuropsychological Society: JINS, 16(3), 54655. doi:10.1017/S1355617710000172

Johnson, M. K., Hashtroudi, S., \& Lindsay, D. S. (1993). Source monitoring. Psychological Bulletin, 114(1), 3-28. doi:10.1037/0033-2909.114.1.3

Johnson, S. C., Ries, M. L., Hess, T. M., Carlsson, C. M., Gleason, C. E., Alexander, A. L., ... Sager, M. A. (2007). Effect of Alzheimer disease risk on brain function during self- 
appraisal in healthy middle-aged adults. Archives of General Psychiatry, 64(10), 1163 1171. doi:10.1001/archpsyc.64.10.1163

Kalenzaga, S., Bugaïska, A., \& Clarys, D. (2013). Self-reference effect and autonoetic consciousness in Alzheimer disease: Evidence for a persistent affective self in dementia patients. Alzheimer Disease and Associated Disorders, 27(2), 116-122. doi:10.1097/WAD.0b013e318257dc31

Kalenzaga, S., \& Clarys, D. (2013). Self-referential processing in Alzheimer's disease: Two different ways of processing self-knowledge? Journal of Clinical and Experimental Neuropsychology, 35(5), 455-471. doi:10.1080/13803395.2013.789485

Kalenzaga, S., Piolino, P., \& Clarys, D. (2014). The emotional memory effect in Alzheimer's disease: Emotional words enhance recollective experience similarly in patients and control participants. Cognition \& Emotion, 29(2), 342-350. doi:10.1080/02699931.2014.907127

Katsuno, T. (2005). Dementia from the inside: How people with early-stage dementia evaluate their quality of life. Ageing and Society, 25(2), 197-214. doi:10.1017/S0144686X0400279X

Kelley, W. M., Macrae, C. N., Wyland, C. L., Caglar, S., Inati, S., \& Heatherton, T. F. (2002). Finding the self? An event-related fMRI study. Journal of Cognitive Neuroscience, 14(5), 785-794. doi:10.1162/08989290260138672

Kensinger, E. A. (2004). Remembering emotional experiences: The contribution of valence and arousal. Reviews in the Neurosciences, 15(4), 241-251. Retrieved from http://www.ncbi.nlm.nih.gov/pubmed/15526549 
Kensinger, E. A., Brierley, B., Medford, N., Growdon, J. H., \& Corkin, S. (2002). Effects of normal aging and Alzheimer's disease on emotional memory. Emotion, (Washington, D.C.), 2(2), 118-134.

Kitwood, T., \& Bredin, K. (1992). Towards a theory of dementia care: Personhood and wellbeing. Ageing and Society, 12, 269-287. Retrieved from http://www.ncbi.nlm.nih.gov/pubmed/11654434

Klein, S. B., Cosmides, L., \& Costabile, K. A. (2003). Preserved knowledge of self in a case of Alzheimer's dementia. Social Cognition, 21(2), 157-165.

Klein, S. B., \& Gangi, C. E. (2010). The multiplicity of self: Neuropsychological evidence and its implications for the self as a construct in psychological research. Annals of the New York Academy of Sciences, 1191, 1-15. doi:10.1111/j.1749-6632.2010.05441.x

Koutstaal, W., \& Schacter, D. L. (1997). Inaccuracy and inaccessibility in memory retrieval: Contributions from cognitive psychology and neuropsychology. In P. S. Appelbaum, L. A. Uyehara, and M. R. Elin (Eds.), Trauma and memory: Clinical and legal controversies(pp. 93-137). New York: Oxford University Press.

Kuiper, N. A., \& Derry, P. A. (1982). Depressed and nondepressed content self-reference in mild depressives. Journal of Personality, 50(1), 67-80. Retrieved from http://www.ncbi.nlm.nih.gov/pubmed/7086630

La Joie, R., Landeau, B., Perrotin, A., Bejanin, A., Egret, S., Pélerin, A., ... Chételat, G. (2014). Intrinsic connectivity identifies the hippocampus as a main crossroad between Alzheimer's and semantic dementia-targeted networks. Neuron, 81(6), 1417-28. doi:10.1016/j.neuron.2014.01.026

La Joie, R., Perrotin, A., Barré, L., Hommet, C., Mézenge, F., Ibazizene, M., ... Chételat, G. (2012). Region-specific hierarchy between atrophy, hypometabolism, and $\beta$-amyloid 
(A $\beta$ ) load in Alzheimer's disease dementia. The Journal of Neuroscience, 32(46), 16265-16273. doi:10.1523/JNEUROSCI.2170-12.2012

La Joie, R., Perrotin, A., de La Sayette, V., Egret, S., Doeuvre, L., Belliard, S., ... Chételat, G. (2013). Hippocampal subfield volumetry in mild cognitive impairment, Alzheimer's disease and semantic dementia. NeuroImage: Clinical, 3, 155-. doi:10.1016/j.nicl.2013.08.007

Lalanne, J., Rozenberg, J., Grolleau, P., \& Piolino, P. (2013). The self-reference effect on episodic memory recollection in young and older adults and Alzheimer's disease. Current Alzheimer Research, 10(10), 1107-1117. Retrieved from http://www.ncbi.nlm.nih.gov/pubmed/24156261

Langdon, S. A., Eagle, A., \& Warner, J. (2007). Making sense of dementia in the social world: A qualitative study. Social Science \& Medicine), 64(4), 989-1000. doi:10.1016/j.socscimed.2006.10.029

Maki, Y., Yoshida, H., Yamaguchi, T., \& Yamaguchi, H. (2013). Relative preservation of the recognition of positive facial expression "happiness" in Alzheimer disease. International Psychogeriatrics / IPA, 25(1), 105-110. doi:10.1017/S1041610212001482

Mather, M., \& Carstensen, L. L. (2003). Aging and attentional biases for emotional faces. Psychological Science, 14(5), 409-415. doi:10.1111/1467-9280.01455

Mather, M., \& Carstensen, L. L. (2005). Aging and motivated cognition: The positivity effect in attention and memory. Trends in Cognitive Sciences, 9(10), 496-502. doi:10.1016/j.tics.2005.08.005

Mattis, S. (1976). Mental status examination for organic mental syndrome in the elderly patient. In L. Bellack, \& T.B. Karusu (Eds.), Geriatric psychiatry: A handbook for psychiatrist and primary care physicians (pp. 77-121). New York: Grune \& Straton. 
McKhann, G., Drachman, D., Folstein, M., Katzman, R., Price, D., \& Stadlan, E. M. (1984). Clinical diagnosis of Alzheimer's disease: Report of the NINCDS-ADRDA Work Group under the auspices of Department of Health and Human Services Task Force on Alzheimer's Disease. Neurology, 34(7), 939-944. Retrieved from http://www.ncbi.nlm.nih.gov/pubmed/6610841

Montgomery, S. A., \& ̊̊sberg, M. (1979). A new depression scale designed to be sensitive to change. The British Journal of Psychiatry, 134, 382-389. Retrieved from http://www.ncbi.nlm.nih.gov/pubmed/444788

Moran, J. M., Heatherton, T. F., \& Kelley, W. M. (2009). Modulation of cortical midline structures by implicit and explicit self-relevance evaluation. Social Neuroscience, 4(3), 197-211. doi:10.1080/17470910802250519

Morel, N., Villain, N., Rauchs, G., Gaubert, M., Piolino, P., Landeau, B., ... Chételat, G. (2014). Brain activity and functional coupling changes associated with self-reference effect during both encoding and retrieval. PloS One, 9(3), e90488. doi:10.1371/journal.pone.0090488

Mueller, J. H., Wonderlich, S., \& Dugan, K. (1986). Self-referent processing of age-specific material. Psychology and Aging, 1(4), 293-299.

Naylor, E., \& Clare, L. (2008). Awareness of memory functioning, autobiographical memory and identity in early-stage dementia. Neuropsychological Rehabilitation, 18(5-6), 590606. doi:10.1080/09602010701608681

Neisser, U., \& Libby, L. K. (2000). Remembering life experiences. In E. Tulving, \& F. I. M. Craik (Eds.), The Oxford handbook of memory (pp. 315-332). New York: Oxford University Press. 
Perri, R., Carlesimo, G. A., Serra, L., \& Caltagirone, C. (2005). Characterization of memory profile in subjects with amnestic mild cognitive impairment. Journal of Clinical and Experimental Neuropsychology, 27(8), 1033-55. doi:10.1080/13803390490919317

Perrotin, A., Desgranges, B., Landeau, B., Mézenge, F., La Joie, R., Egret, S., ... Chételat, G. (2015). Anosognosia in Alzheimer disease: Disconnection between memory and self networks. Annals of Neurology. doi:10.1002/ana.24462

Petersen, R. C. (2003). Mild cognitive impairment clinical trials. Nature Reviews. Drug Discovery, 2(8), 646-653. doi:10.1038/nrd1155

Petersen, R. C., Doody, R., Kurz, A., Mohs, R. C., Morris, J. C., Rabins, P. V., ... Winblad, B. (2001). Current concepts in mild cognitive impairment.Archives of Neurology, 58(12), 1985-1992. doi:10.1001/archneur.58.12.1985

Petersen, R. C., \& Morris, J. C. (2005). Mild cognitive impairment as a clinical entity and treatment target. Archives of Neurology, 62(7), 1160-1163; discussion 1167. doi:10.1001/archneur.62.7.1160

Petersen, R. C., Smith, G. E., Waring, S. C., Ivnik, R. J., Tangalos, E. G., \& Kokmen, E. (1999). Mild cognitive impairment: Clinical characterization and outcome. Archives of Neurology, $\quad$ 56(3), $\quad 303-308 . \quad$ Retrieved $\quad$ from http://www.ncbi.nlm.nih.gov/pubmed/10190820

Rankin, K. P., Baldwin, E., Pace-Savitsky, C., Kramer, J. H., \& Miller, B. L. (2005). Self awareness and personality change in dementia. Journal of Neurology, Neurosurgery, and Psychiatry, 76(5), 632-639. doi:10.1136/jnnp.2004.042879

Rauchs, G., Piolino, P., Mézenge, F., Landeau, B., Lalevée, C., Pélerin, A., ... Desgranges, B. (2007). Autonoetic consciousness in Alzheimer's disease: Neuropsychological and PET 
findings using an episodic learning and recognition task. Neurobiology of Aging, 28(9), 1410-1420. doi:10.1016/j.neurobiolaging.2006.06.005

Reed, A. E., \& Carstensen, L. L. (2012). The theory behind the age-related positivity effect. Frontiers in Psychology, 3, 339. doi:10.3389/fpsyg.2012.00339

Ribeiro, F., Guerreiro, M., \& De Mendonça, A. (2007). Verbal learning and memory deficits in Mild Cognitive Impairment. Journal of Clinical and Experimental Neuropsychology, 29(2), 187-97. doi:10.1080/13803390600629775

Rogers, T. B., Kuiper, N. A., \& Kirker, W. S. (1977). Self-reference and the encoding of personal information. Journal of Personality and Social Psychology, 35(9), 677-688. Retrieved from http://www.ncbi.nlm.nih.gov/pubmed/909043

Rosa, N. M., Deason, R. G., Budson, A. E., \& Gutchess, A. H. (2015). Self-Referencing and False Memory in Mild Cognitive Impairment Due to Alzheimer's Disease. Neuropsychology. doi:10.1037/neu0000186

Sabat, S. R., \& Harré, R. (1992). The construction and deconstruction of self in Alzheimer's disease. Ageing and Society, 12(04), 443-461. doi:10.1017/S0144686X00005262

Salmon, D. P., \& Bondi, M. W. (2009). Neuropsychological assessment of dementia. Annual Review of Psychology, 60, 257-82. doi:10.1146/annurev.psych.57.102904.190024

Sanz, J. (1996). Memory biases in social anxiety and depression. Cognition \& Emotion, 10(1), 87-106. doi:10.1080/026999396380402

Scheier, M. F., \& Carver, C. S. (1985). Optimism, coping, and health: Assessment and implications of generalized outcome expectancies. Health Psychology, 4(3), 219-247. Retrieved from http://www.ncbi.nlm.nih.gov/pubmed/4029106 
Sedikides, C., \& Green, J. D. (2000). On the self-protective nature of inconsistency-negativity management: Using the person memory paradigm to examine self-referent memory. Journal of Personality and Social Psychology, 79(6), 906-922. Retrieved from http://www.ncbi.nlm.nih.gov/pubmed/11138760

Sedikides, C., \& Green, J. D. (2004). What I don't recall can't hurt me: Information negativity versus information inconsistency as determinants of memorial self-defense. Social Cognition, 22(1), 4-29. doi:10.1521/soco.22.1.4.30987

Signoret, J.-L. (1991). Batterie d'efficience mnésique, BEM 144. Paris: Elsevier.

Song, J., Ahn, I. S., Kang, H. S., Myung, W., Lee, Y., Woo, S., ... Kim, D. K. (2014). Cognitive subdomain responses to galantamine in Alzheimer's disease. The Journal of Nervous and Mental Disease, 202(3), 253-259. doi:10.1097/NMD.0000000000000107

Sørensen, L. V, Waldorff, F. B., \& Waldemar, G. (2008). Early counselling and support for patients with mild Alzheimer's disease and their caregivers: A qualitative study on outcome. Aging \& Mental Health, 12(4), 444-450. doi:10.1080/13607860802224342

Symons, C. S., \& Johnson, B. T. (1997). The self-reference effect in memory: A metaanalysis. Psychological Bulletin, 121(3), 371-394. Retrieved from http://www.ncbi.nlm.nih.gov/pubmed/9136641

Tulving, E. (1985). Memory and consciousness. Canadian Psychology, 26(1), 1-12.

Tulving, E. (2002). Episodic memory: From mind to brain. Annual Review of Psychology, 53, 1-25. doi:10.1146/annurev.psych.53.100901.135114

Van der Linden, M., \& Juillerat, A.-C. (2004). [Neuropsychological rehabilitation in early stage Alzheimer's disease: Principles, methods and perspectives]. Revue Neurologique, 160(4, Pt 2), S64-70. Retrieved from http://www.ncbi.nlm.nih.gov/pubmed/15118554 
Werheid, K., Gruno, M., Kathmann, N., Fischer, H., Almkvist, O., \& Winblad, B. (2010). Biased recognition of positive faces in aging and amnestic mild cognitive impairment. Psychology and Aging, 25(1), 1-15. doi:10.1037/a0018358

Werheid, K., McDonald, R. S., Simmons-Stern, N., Ally, B. A.,\& Budson, A. E. (2011). Familiar smiling faces in Alzheimer's disease: Understanding the positivity-related recognition bias. Neuropsychologia, 49(10), 2935-2940. doi:10.1016/j.neuropsychologia.2011.06.022

Winblad, B., Palmer, K., Kivipelto, M., Jelic, V., Fratiglioni, L., Wahlund, L.-O., ... Petersen, R. C. (2004). Mild cognitive impairment--beyond controversies, towards a consensus: report of the International Working Group on Mild Cognitive Impairment. Journal of Internal Medicine, 256(3), 240-6. doi:10.1111/j.1365-2796.2004.01380.x

\section{Figure captions}

Fig. 1. Illustration of the memory task. The incidental encoding phase was divided into two parts, each lasting roughly 7 minutes, during which participants had to determine whether the adjective displayed described them (self-referential condition) or a celebrity (otherreferential condition), or whether it was a positive adjective or not(semantic condition). 
Adjectives were displayed on a screen one at a time for $3500 \mathrm{~ms}$, followed by a fixation cross for 1000-3000 ms. Participants answered "Yes" or "No" with their right and left index fingers (counterbalanced across participants) using keypads. They were reminded of which side corresponded to which answerat the bottom of the screen. The recognition phasecame immediately after the incidental encoding session. Previously encountered adjectives (old ones) were mixed with distractors (new ones). Presentation of the adjectives was similar to that of the previous session (adjectives were presented on a screen one at a time for $3500 \mathrm{~ms}$ ). Participants had to decide whether or not they had already seen each adjective during the incidental encoding session.

Fig. 2.Mean accuracy scores (proportion of hits minus proportion of false alarms) for negative and positive adjectives encoded with reference to the self or a distant other,or processed semantically, for HC and patients with aMCI. Error bars indicate standard errors of the mean (SEMs). $* p<.05 . * * p<.01 . * * * p<.001$. 